\title{
"From Teaching to Learning": Characteristics and Challenges of a Student-Centered Learning Culture
}

\section{Carmen Wulf}

Inquiry-based learning is part of the tradition of the much-discussed "shift from teaching to learning" (Barr and Tagg 1995), which calls for the learning culture to be oriented towards a student-centered view. This transition is not a new phenomenon. However, it has gained popularity, particularly since the start of the Bologna Process and discussions of higher education didactics at European institutions of higher learning. As such, learning culture, as a concept, should be examined and defined from various perspectives (Schüßler and Thurnes 2005). In the following article, I will present a holistic view of learning processes using the term "learning culture."

In a knowledge-based society, current specialist knowledge quickly becomes outdated, and so it is important for university education to impart abilities and skills to students which will allow them to acquire knowledge autonomously and learn to manage uncertainties. In this context, the importance of conveying merely content-based knowledge decreases; the focus is increasingly on conveying key competencies. Formats in the sense of student-centered learning culture, for example inquiry-based learning, are considered especially suitable for fostering key competencies such as self-guided learning.

In order to present a student-centered learning culture, I will first examine the theoretical approach of learning as a construct, subsequently explain the characteristics of this learning culture and then discuss the challenges inherent in a transition in the learning culture.

C. Wulf, Dr., Dipl.-Psych. $(\bowtie)$

Carl von Ossietzky Universität Oldenburg, Institut für Pädagogik, Fachgruppe

Forschungsmethoden in den Erziehungs- und Bildungswissenschaften, Oldenburg, Germany e-mail: carmen.wulf@uni-oldenburg.de 


\subsection{Constructivist Learning Approaches as a Theoretical Background to a Student-Centered Learning Culture}

A student-centered learning culture is oriented towards a "constructivist" view of learning, without ignoring the fact that this is not an autonomous learning theory, but rather an epistemological position that is applied to different contexts. Constructivist perspectives on learning are closely related to the progressive educational remarks by John Dewey (18591952), the humanistic psychology of Carl Rogers (1902-1987) or the developmental psychology research of Piaget (1896-1980) and unify assumptions about teaching, learning and the resulting learning environments. In summary, constructivist approaches consider the acquisition of knowledge to be a constructive, active, self-guided, social and situational process (cf. Reinmann-Rothmeier and Mandl 1997; Reinmann and Mandl 2006). Some of the principles of a student-centered learning culture will be presented below.

Learning as a constructive process: Learning processes take place in the individual interpretation and construction of meaning, and occur either as a result of connecting new experiences with existing constructs or by expanding existing constructs (in the sense of an assimilation and accommodation according to Piaget). New information must be related to already acquired impressions and elements. Since each individual draws on different experiences and different prior knowledge in order to process new information, knowledge structures represent individual interpretations of reality.

Learning as an active processing of content: Cognitive learning theories focus on the way new knowledge is cognitively processed (Ausubel 1968). While these theories primarily regard learning as a way to process information to be assimilated and stored by learners, constructivist approaches assume that knowledge cannot be transmitted; instead, every learner must recreate knowledge. When perceptions and knowledge do not represent a subject-independent reality, but are rather individual constructs, these have a personal, private character that cannot be transferred from one person to another. Thus it is not possible to learn by passively taking in information - instead, learning can only be achieved by engaging in an active examination of learning content and integrating individual experiences and knowledge backgrounds.

Learning is self-regulated: Learning is initiated and fostered when it is self-regulated, i.e. when learners are able to decide for themselves when, what and how they learn. From a constructivist perspective, learners should determine their learning process independently to the greatest extent possible, coordinated with their own interests and previous knowledge, just that an active process of construction can be initiated.

Learning as a cooperative process: In constructivist theories, social interactions are a core element, since learning occurs in a communicative form through engagement with others: In every learning process, not only is content exchanged, but expectations, attitudes and moods are also transmitted as indirect messages. Students and teachers, as well as students among themselves, have reciprocal effects on one another so that "learning in relationships" represents an essential part of conceptions about learning. 
Learning content is situational: Instruction-oriented, traditional transfer of knowledge often results in the phenomenon known as "sluggish knowledge" (Reinmann-Rothmeier and Mandl 1997, p. 364), meaning the inadequate transfer of theoretical knowledge to other contexts. One explanation for this phenomenon is the situatedness of the knowledge acquired: Learning always occurs within a specific context and is therefore linked with this context. Accordingly, the difficulty of transferring knowledge to other contexts is regarded as a "normal" problem in learning processes and should be resolved by designing the learning environments appropriately. In order to minimize the discrepancy between knowledge and behavior, learning should always occur in contexts that are oriented as much as possible towards later application contexts in terms of content and structure. Didactic formats that take this into consideration are conceptually grouped together as "situated cognition" approaches (Reinmann and Mandl 2006).

These aspects are generally of decisive importance for any learning process, but they are weighted even more heavily in adult education, since aspects such as independent activity, taking one's own interests into account and prior experience, as well as reference to concrete situations, are especially important (Reinmann-Rothmeier and Mandl 1997, p. 356). Moreover, in contrast to learning environments in school, learning environments in higher education are characterized by a greater heterogeneity of learner types in terms of individual previous knowledge, cognitive prerequisites, learning strategies, motivation, attitudes and expectations (Viebahn 2008). Constructivist learning approaches provide the opportunity to consider this diversity and to support the learning process for all students.

\subsection{Characteristics of a Student-Centered Learning Culture}

A student-centered learning culture involves a paradigm shift that is characterized by a constructivist perception of learning processes and that distinguishes itself from a more instruction-centered learning culture in terms of the design of learning objectives and associated performance assessment and learning structures, as well as the role designs for educators and learners (Barr and Tagg 1995). Based on various observations of the transition in learning culture and of student-centered learning, in which the focus of each is emphasized (Barr and Tagg 1995; Lea et al. 2003; O’Neill and McMahon 2005; Taylor 2013), it is possible to derive the following definition:

A student-centered learning culture is oriented on constructivist findings, considering the activity of learners in the process of knowledge acquisition; emphasizes self-regulated and autonomous learning processes that take place in social interaction; takes into account social, emotional and motivational aspects of the learning process in addition to cognitive factors; is responsive to varying prior knowledge and experiences; and involves an emancipated relationship between educators and learners in an open and flexible, competence-oriented learning environment. 
From a constructivist perspective, learning is always an active process, meaning a direct transmission of knowledge from teacher to learner is not possible. The focus, when considering learning processes, must therefore be on the learners and their learning activities, rather than (as is the case in an instruction-centered learning culture) on the educators and the structuring of content. Specific learning objectives within the context of a studentcentered learning culture are associated with this focus: Kowledge transfer-in the sense of providing students with "correct" answers to questions - takes a back seat; instead, it becomes more about teaching students how to proceed in order to obtain answers to questions autonomously. Imparting learning strategies, techniques and attitudes that foster learning are most important. Thus, the core focus of a student-centered learning culture is to promote key competencies such as self-regulated learning, critical thinking or teamwork.

In addition, one aim of student-centered learning culture is to foster deep learning and understanding (deep approaches to learning) and intrinsic learning motivation (Baeten et al. 2013; Lea et al. 2003). Deep approaches to learning involve intensive study of the subject matter with a focus on understanding the content as opposed to just memorizing the learning material. Deep approaches of this kind require learning strategies by which new information can be related to the knowledge that learners already possess. Motivational components are positively related to the application of deep approaches to learning, and indirectly influence the learning process by moderating the selection of tasks or the effort invested (Baeten et al. 2010). Self-determined motivation-in the meaning of Deci and Ryan (1993) - appears to be especially encouraging for learning processes.

Since, in a student-centered learning culture, learning is considered as an active, individual construction, it is also implicitly assumed that heterogeneity among students could be better taken into account and that it will thus be possible to better enhance their learning (Barr and Tagg 1995) — an aspect that is of great significance in terms of higher education policy. Building on constructivist learning approaches, this involves coordinating teaching and learning formats with the needs, previous knowledge and experiences of the students.

Moreover, with its orientation toward student activities, a student-centered learning culture focuses on competence-orientation as a learning outcome (Attard et al. 2010; Barr and Tagg 1995). The essential outcome is not what is taught (i.e. which and how many courses are provided by educators), but what the student learns. As such, the objectives are more closely oriented toward the learning outcomes at the end of the course (e.g. students are able to classify basic procedures) and less toward the transmission of specific content (e.g. students will be imparted basic procedures).

With regard to concrete learning formats in a student-centered learning culture, enormous methodological diversity is possible. Although student-centered learning is often mentioned with reference to learning formats such as inquiry-based learning, problembased learning or discovery learning, it is not possible to deduce the individual didactic formats directly from the characteristics or to avoid instruction-oriented formats such as 
lectures. The recommendations of the moderate constructivist view of learning are oriented towards uniting instruction and construction (Reinmann and Mandl 2006).

The orientation towards a student-centered learning culture is accompanied by the design of specific roles for educators and learners. In a more instruction-centered learning culture, the role of educators is to present and explain new information, to guide learners and to monitor and evaluate the learning progress. According to this view, learners are assigned a rather passive position, in which external control and monitoring are required for successful learning. In a student-centered learning culture, students are allocated a much more active role. Students are part of a community of learners and educators, independently helping to shape their learning process and take ownership of their own learning progress. As a result, in this approach, autonomous and self-regulated learning is of great importance.

The role of educators is to provide learners with encouragement, support and advice. Educators must recognize learners' individual needs, provide appropriate "tools" for the learning processes and encourage engagement with other learners. In a student-centered learning culture, educators are learning guides. In this sense they are conceived primarily as experts for designing and adjusting learning environments to students' experiences and previous knowledge, thereby enhancing self-regulated learning. Actions are guided less by questions such as "How can I convey the material and present it in a well-structured manner?" and more by questions such as "How can I facilitate learning and encourage learning activities, and thus make it possible for students to engage in independent learning?" The role of educators is thus conceived as much more restrained than in a primarily instructionoriented learning culture, since the focus is less on the educator's well-structured and professionally competent lecture than on the educator as role model, facilitator, and advisor to the learning processes. Barr and Tagg (1995) describe this change in roles using the analogy of the soccer coach, who not only gives the players instructions as to how they should play, but also designs training concepts and strategies and actively supports them during the game, for example with technical decisions. In a similar sense, educators should shape learning environments and use their skills to create the best possible learning atmosphere.

\subsection{Challenges of a Student-Centered Learning Culture}

A student-centered transition in the learning culture is a clear goal of the Bologna Process. The format, including its objectives, is particularly suitable for adult learners, is geared to the needs of lifelong learning, and should replace what has previously been an excessively instruction-oriented and insufficiently student-oriented learning culture. A number of studies indicate a positive effect in terms of promoting deep approaches to learning, selfmotivation and student diversity (cf. Lea et al. 2003 for an overview). However, 
student-centered learning approaches have been viewed critically in recent years (O'Neill and McMahon 2005; Taylor 2013, amongst others) because it seems that such approaches are not equally appropriate for all students; the demands on educators and structural factors are very stringent; and the findings on the desired effects are contradictory. For example, students are very accustomed to "traditional" forms of teaching and often prefer reproductive, instruction-oriented learning (Reinmann-Rothmeier and Mandl 1997). Even by adapting the learning environment, it is only possible to change this orientation slightly (Baeten et al. 2013). In their study, Brahm and Gebhardt (2011) also found that students rely heavily on the guidance, control and supervision of an instructor. Such an attitude inhibits the implementation and success of a student-centered learning culture.

The ability and willingness to engage in self-regulated learning, which is of particular importance in student-centered contexts, is influenced by cognitive, metacognitive and motivational components (Boekaerts 1996), while how pronounced these are varies from student to student (Viebahn 2008). It appears that particular students who already display appropriate attributes at the beginning of their academic studies-i.e. good cognitive abilities, high level of self-motivation and pronounced use of deep approaches to learningbenefit from a student-centered learning culture (Baeten et al. 2010). If the attempt to secure and activate basic (preliminary) knowledge is unsuccessful, there is a risk that a student-centered learning culture will be regarded as lacking structure and will overwhelm students. Similarly, evidence on the effects of student-centered learning environments demonstrates that the original learning orientation — surface learning or deep learningimpacts the efficacy of learning, and students who originally have a surface learning orientation are less likely to engage in deep learning (Baeten et al. 2010).

With regard to motivational components, self-motivation is ascribed great importance within the context of self-regulated learning (Deci and Ryan 1993). On average, students tend toward self-guided motivation (Wulf 2013); however, some students have a more extrinsic learning orientation and thus lack an essential prerequisite for self-guided learning. Furthermore, differences in self-determined motivation can be identified: For example, in a study comparing various subjects, students of social work or special-needs education showed significantly greater self-motivation than those engaged in teaching certification programs or social sciences (Wulf 2013).

An additional challenge in a student-centered learning culture is to what extent selfstudy activities are prioritized. With the Bologna reform, the envisioned time expenditure for reaching learning objectives has been identified as a workload comprised of time allotments for active class attendance and self-study. In addition to time spent in active class attendance, intensive, individual learning is expected of students in their role as active learners. Findings from various studies indicate a low overall incidence of self-study, however, which frequently occurs only during exam times (Schulmeister and Metzger 2011). Initial results of our own longitudinal survey over the course of the semester regarding a module in the format of inquiry-based learning likewise point to a low proportion of selfstudy, which is on average about $2 \mathrm{~h}$ per week with a high degree of individual variability. 
Another problem appears to be that student-centered learning formats are perceived as more complex and this perception can lead to a negative attitude among students (Baeten et al. 2010).

\subsection{Conclusion}

Various consequences can be derived from the characteristics of student-centered learning and the challenges for learners and educators.

With regard to the role of students, it seems particularly necessary to make the expectations and requirements for autonomy and self-guidance of learning transparent. Since student-centered learning formats are perceived as more complex and since this perception can lead to a negative attitude that prevents deep learning, the paradigm shift (including its goals) and the didactic structure must be made transparent if it is to be accepted by all students. In order to balance differences in previous knowledge, there will be a continued need for additional courses related to certain modules and the learning objectives thereof, but which are not obligatory for all students. The phases of independent learning should be clearly stated in the curriculum and discussed with the students at the beginning of the courses, as the time expenditure for self-study would otherwise only be utilized to a small extent, which, instead of contributing to the deep understanding of the content, may instead promote strategies associated with surface learning.

Due to the focus on student learning activities as well as the competence orientation, it is necessary for a student-centered learning culture to readjust concepts regarding evaluation. Here, it would be possible to orient ourselves on evaluation models such as those that have been used in the United States for more than a decade in the National Survey of Student Engagement (Kuh 2001). All student activities serve as indicators of competence orientation, i.e. it is assumed that students' academic competence and thus their learning success are reflected in the extent to which students practice and carry out study-related activities (Messner et al. 2009; Winteler and Forster 2008).

In terms of the role requirements for educators, a high degree of teaching-related engagement, a generally student-centered attitude as well as a high level of technical and didactic competence appear to be necessary requirements for promoting a transition in the learning culture. Since the amount of preparation and support required in student-centered forms of learning is significantly higher and less tied to the time spent in active class attendance, this must be taken into account when calculating teaching capacities. The existing calculation using the number of courses provided clearly corresponds to an instructionoriented paradigm and does not take into account the various degrees of effort associated with the individual learning formats or generally associated with a student-centered learning culture.

Furthermore, courses in higher education didactics should be extended to those status groups that have not only been excluded from such by the university culture, but for whom 
such activities also carry little weight for university career paths. Although teaching engagement is taken into account more clearly in job placement decisions, at least in individual disciplines (e.g. teaching portfolios, evaluation records, sample teaching, teaching awards, etc.), the primary focus is still on research activities.

\section{References}

Attard, A./Di Ioio, E./Geven, K./Santa, R. (2010). Student Centered Learning. An Insight into Theory and Practice. Bukarest: Education International, European Students Union.

Ausubel, D. P. (1968). Educational Psychology: A Cognitive View. New York: Holt.

Baeten, M./Dochy, F./Struyven, K. (2013). The effects of different learning environments on students' motivation for learning and their achievement. British Journal of Educational Psychology, 83(3), 484-501.

Baeten, M./Kyndt, E./Struyven, K./Dochy, F. (2010). Using student-centred learning environments to stimulate deep approaches to learning: Factors encouraging or discouraging their effectiveness. Educational Research Review, 5, 243-260.

Barr, R. B./Tagg, J. (1995). From Teaching to Learning - A New Paradigm for Undergraduate Education, Change, Nov./Dec., 13-25.

Boekaerts, M. (1996). Self-regulated Learning at the Junction of Cognition and Motivation. European Psychologist, 1(2), 100-112.

Brahm, T./Gebhardt, A. (2011). Motivation deutschsprachiger Studierender in der »Bologna-Ära Zeitschrift für Hochschulentwicklung, 6(2), 15-29.

Deci, E. L./Ryan, R. M. (1993). Die Selbstbestimmungstheorie der Motivation und ihre Bedeutung für die Pädagogik. Zeitschrift für Pädagogik, 39(2), 223-238.

Kuh, G. D. (2001). Assessing what really matters to student learning. Change, May/June, 10-17.

Lea, S./Stephenson, D./Troy, J. (2003). Higher education students' attitudes to student centred learning: beyond 'educational bulimia'. Studies in Higher Education, 28(3), 321-334.

Messner, H./Niggli, A./Reusser, K. (2009). Hochschule als Ort des Selbststudiums - Spielräume für selbstgesteuertes Lernen. Beiträge zur Lehrerbildung, 27(2), 149-162.

O'Neill, G./McMahon, T. (2005). Student-centred learning: What does it mean for students and lecturers? In G. O'Neill/S. Moore/B. Mc Mullin (Hrsg.), Emerging issues in the practice of university learning and teaching (pp. 27-36). Dublin: AISHE.

Reinmann-Rothmeier, G./Mandl, H. (1997). Lehren im Erwachsenenalter: Auffassungen vom Lehren und Lernen, Prinzipien und Methoden. In F. E. Weinert/H. Mandl (Hrsg.), Enzyklopädie der Psychologie: Psychologie der Erwachsenenbildung. (S. 355-390). Göttingen: Hogrefe.

Reinmann, G./Mandl, H. (2006). Unterrichten und Lernumgebungen gestalten. In A. Krapp/B. Weidenmann (Hrsg.), Pädagogische Psychologie - Ein Lehrbuch (S. 613-658). Weinheim: Beltz PVU.

Schulmeister, R./Metzger, C. (Hrsg.). (2011). Die Workload im Bachelor: Zeitbudget und Studierverhalten. Eine empirische Studie. Münster: Waxmann.

Schüßler, I./Thurnes, C. M. (2005). Lernkulturen in der Weiterbildung. Bielefeld: Bertelsmann.

Taylor, J. (2013). What is student-centredness and is it enough? The International Journal of the First Year in Higher Education, 4(2), 39-48.

Viebahn, P. (2008). Lernerverschiedenheit und soziale Vielfalt im Studium. Differentielle Hochschuldidaktik aus psychologischer Sicht. Bielefeld: Webler. 
Winteler, A./Forster, P. (2008). Lern-Engagement der Studierenden. Indikator für die Qualität und Effektivität von Lehre und Studium. Das Hochschulwesen, 56(6), 162-170.

Wulf, C. (2013). Motivationale Voraussetzungen Studierender für Forschendes Lernen. Vortrag im Rahmen der Tagung »Forschendes Lernen: Forum für gute Lehre«, Fachhochschule Potsdam (02.-03.09.2013).

Open Access This chapter is licensed under the terms of the Creative Commons AttributionNonCommercial-NoDerivatives 4.0 International License (http://creativecommons.org/licenses/bync-nd/4.0/), which permits any noncommercial use, sharing, distribution and reproduction in any medium or format, as long as you give appropriate credit to the original author(s) and the source, provide a link to the Creative Commons licence and indicate if you modified the licensed material. You do not have permission under this license to share adapted material derived from this chapter or parts of it.

The images or other third party material in this chapter are included in the chapter's Creative Commons licence, unless indicated otherwise in a credit line to the material. If material is not included in the chapter's Creative Commons licence and your intended use is not permitted by statutory regulation or exceeds the permitted use, you will need to obtain permission directly from the copyright holder.

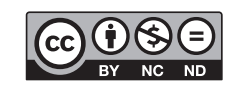

